\title{
Exploring nonprofit dilemmas through a new lens: Introduction to the symposium on experimental and behavioral approaches in nonprofit and voluntary sector research
}

\author{
Mirae Kim*, Kelly LeRoux, Dyana P. Mason ${ }^{\ddagger}$
}

\begin{abstract}
Experimental studies have just begun to diffuse slowly in nonprofit research, reflecting the general recognition that experimental studies can help nonprofit researchers overcome some limitations of the methods that have traditionally been used. This special issue includes four papers that consider the diversity of experimental research in nonprofit studies. First, a systematic literature review of experimental studies in fundraising provides a nice overview of how experimental studies have been adopted for nonprofit research. The other three articles in this symposium cover important topics that have garnered growing attention in the field of nonprofit management --promoting diversity, donor resistance to the overhead myth, and the role of nudging in crowdfunding donations. Taken together, the four articles in this symposium strengthen our understanding of how experimental approaches can address some of the most pressing questions for the nonprofit and voluntary sector. The studies covered here suggest nearly limitless potential applications of properly designed experimental studies to address unique nonprofit challenges. The symposium issue articles also help nonprofit researchers to shift the research inquiry to individuals to address nonprofit dilemmas through the behavioral lens.
\end{abstract}

Keywords: Symposium introduction, Behavioral, Donor, Nonprofit

$\mathrm{N}_{\mathrm{s}}$ onprofit organizations cover a wide range of activities and vary greatly in size. However, due to unobserved factors that are not easily controlled in non-experimental research, studies have often produced ambiguous results with respect to the causality and the strength of the relationship between two factors. Experimental studies offer an opportunity to address the limitations of observational studies and can explore alternative explanations for observed organizational and individual behavior. For example, experimental studies may be able to address decisions among nonprofits to create rainy day funds, why or why not nonprofits enter into a partnership with corporations, what makes nonprofit managers allocate more or less resources to administrative functions, whether donors are indeed discouraged by seeing a large percentage of overhead costs, or whether nonprofits can increase voter turnout, among many other topics. Given these strengths, and the rise of experimental research in the field of public management (James, Jilke, \& Van Ryzin, 2017), experimental studies have just begun to diffuse in nonprofit research, but slowly.

Nonprofit and Voluntary Sector Quarterly, the top journal for the field that celebrated its 50th year in 2020, has published only 25 experimental studies thus far. Of those, 21 articles were published in the last 10

\footnotetext{
* George Mason University

† University of Illinois-Chicago

\# University of Oregon

Address correspondence to Mirae Kim at (mkim216@gmu.edu)

Copyright: (c) 2021. The authors license this article under the terms of the Creative Commons Attribution 4.0

International License.
} 
years with 4 published in 2020. We noticed a similar trend in other nonprofit journals like VOLUNTAS and Nonprofit Management and Leadership. The trend reflects the general recognition of the merits that experimental studies can help nonprofit researchers overcome some limitations of the methods that have traditionally been used.

There are largely three types of experiments depending on the context in which they are conducted--field experiments, survey experiments, and laboratory experiments (James et al., 2017). Broadly speaking, field experiments occur in naturalistic contexts and thus provide more external validity, while laboratory experiments are more effective for internal validity. Survey experiments refer to the use of random treatments in surveys and can be used in either a field or laboratory setting. While we recommend readers to familiarize themselves with the details of these various types of experiments, such as in James, Jilke, and Van Ryzin (2017), this symposium issue on "Experimental and Behavioral Approaches in Nonprofit and Voluntary Sector Research" showcases all three types of experimental approaches.

In this issue, Bhati and Hansen (2020) provide a systematic literature review of experimental studies in fundraising. Interestingly, they point out that the majority of experimental research on this topic have not come from scholars of nonprofit or public management, but the fields of economics, psychology, and business. Although their review focuses on fundraising activities, it provides a comprehensive view of how experimental studies can answer some of the questions critical for nonprofit researchers and practitioners. It is also worth noting that the topic of fundraising goes beyond simply understanding theories of donor motivation - why and how people give - but there are vitally important practical implications for this knowledge, as donations are the life support for many nonprofits. Even for those organizations not heavily reliant on donations, understanding why people give could signal the mechanisms of building public support and trust for a nonprofit. This review is also instructive for practitioners as it summarizes experiments related to the effectiveness of various fundraising practices and techniques. The authors skillfully distill the findings of 187 experiments they reviewed into ten insights about fundraising, which then pave the way for future research. One of the key contributions in this article is to offer ethical considerations for scholars using experiments to test ideas behind charitable giving. They also point to a critical gap in the research which is a dearth of experiments focused on management of fundraising and development within nonprofits. This presents a promising line of inquiry for nonprofit and public management scholars that has not yet been exploited by other disciplines.

The other three articles in this symposium cover important topics that have garnered growing attention in the field of nonprofit management --promoting diversity, donor resistance to the overhead myth, and the role of nudging in crowdfunding donations. First, van Teunenbroek and Bekkers (2020) used a field experiment to show how social information influences crowdfunding campaigns. These authors test social information theory in the context of a large crowdfunding campaign, and find that social information increases average donation amounts but does not necessarily attract a larger number of donors. Of imminent practical value, their set of experiments identify the precise stage in the fundraising campaign when social information is most effective and useful (at the beginning).

Second, Tian, Hung, and Frumkin (2020) employ a survey experiment in a laboratory setting with university students in a Midwestern urban university. Drawing on agency theory, they describe the information asymmetry that exists between nonprofit leaders who comprehend the full costs of executing the nonprofits mission, and donors who typically do not understand these costs and expect their contributions will cover "direct services." The authors find that donors are indeed resistant to the notion of paying for nonprofit overhead costs but this resistance can be overcome when the donor is provided with information about the organization's performance and transparency. One key takeaway from this experiment for nonprofit practitioners is that nonprofits should confront overhead costs directly in their messaging, rather than working to hide it.

Jurcevic and Fyall (2019) construct a survey experiment to address the critically important topic of how nonprofits frame diversity values for stakeholders. Using MTurk data across two experiments, the authors demonstrate how framing and communicating diversity values within nonprofits can generate different perceptions from potential stakeholders. The authors describe two distinctly different diversity frames, one emphasizing the moral imperative of diversity and the other emphasizing the instrumental value or benefits of diversity. The authors arrive at some findings that, although inconsistent with their hypotheses, are instructive nevertheless. They find that Black and Latino stakeholders feel more devalued by the framing of diversity as a moral imperative as compared with the instrumental frame, whereas white stakeholders perceive the instrumental 
frame as being less authentic. They further find through a second experiment that whites who are anxious about job market prospects tend to feel devalued by the instrumental frame. Taken together these findings show that language matters in the way that nonprofits share diversity messages, and that language may evoke different reactions among stakeholders depending on race.

Finally, the symposium addresses not only why and how experimental approaches can benefit nonprofit research and practice, but provides some options for selecting experimental participants. Testing an idea using experiments requires the recruitment or assignment of participants to either treatment or control groups in a randomized fashion. Laboratory experiments have largely drawn from student samples because of its convenience (Tepe \& Prokop, 2017). Yet, Druckman and Kam (2011) argue that the validity of using students depends largely on the purpose of the experimental study and student samples could offer the same level of experimental realism. In the presence of heterogenous treatment effects between student samples and nonstudent samples, researchers could test an interaction model to detect moderating dynamics. Amazon's Mechanical Turk (MTurk) is one of the increasingly used online labor markets to recruit experimental participants, compensating participants for their time in completing small tasks (Jilke \& Van Ryzin, 2017).

The current symposium issue offers the flavor of these two popular ways to recruit participants in experiments. Tian, Hung and Frumkin (2020) also shows how the authors used university students in order to run an experiment in a laboratory setting. Another one, by Jurcevik \& Fyall (2019) used MTurk to run two experiments. As such, this symposium offers readers a chance to see how different methods could be used in nonprofit research to address some of the challenging issues that could not have been answered in previous, mostly observational studies.

Taken together, the four studies in this symposium strengthen our understanding of how experimental approaches can address some of the most pressing questions for the nonprofit and voluntary sector. The common takeaways from the studies covered here illustrate the importance of communications in addressing critical nonprofit specific issues, such as how to strike a balance between an organization's social mission and the need to become more business-like (Jurcevic \& Fyall, 2019), overcoming overhead starvation cycle (Tian et al., 2020), and how and when social information can enhance fundraising practices, including crowdfunding campaigns (Teunenbroek \& Bekkers, 2020). Without the use of experiments, it is impossible to identify the causal effect of nuanced communications and understand how to structure messages in ways that are effective in eliciting desired responses by various nonprofit stakeholders.

Finally, much of the research in the field of nonprofit studies broadly is situated at the organizational level, with nonprofit organizations serving as the unit of analysis. This issue highlights the utility of a behavioral lens, which shifts the unit of analysis to individuals rather than organizations. This micro-level analytic perspective can be useful for studying the behaviors, motivations, and reactions of many types of individuals that represent critical actors within the sphere of nonprofit and voluntary organizations, including client/patrons/service recipients, employees, volunteers, donors, board members, and others. By shifting our attention to the microlevel of nonprofit organizations and employing experimental methods to understand individuals, we open new lines of inquiry in nonprofit research. More importantly, the nonprofit practice world stands to benefit substantially from the evidence that could be produced.

While the vast majority of experimental studies relevant to nonprofit scholars and practitioners relate to questions of fundraising and donor behavior, there are nearly limitless potential applications of these methods that, when properly designed and executed, can generate valuable insights for nonprofit practice. Nonprofits face unique pressures to demonstrate to funders their social impact, performance, and value. Experimental research is best suited for helping to generate the kind of knowledge that gets to the bottom of the question of "what works?" In shifting the research inquiry to the individuals, we can begin to see nonprofit dilemmas through a new lens. In adopting this perspective, researchers might for example design experiments to ascertain what types of messages are most effective in recruitment materials if the goal is to attract diverse staff, or to attract employees with high public service motivation. There are many types of questions related to staff and volunteer recruitment and retention that might be answered through experiments. What types of behavioral interventions (non-monetary incentives) are most effective for increasing volunteer retention? Experiments may also be applied to gauge the effectiveness of nonprofits' advocacy or political mobilization efforts by measuring activism of clients, staff, or other stakeholders in response to some type of call to action (stimuli) issued by the organization. There are perhaps also pressing questions related to nonprofit governance that 
might be answered through experimental research that examines individual board members, rather than nonprofit boards as collectives. These questions might center on best methods for recruiting and retaining diverse or qualified board members, or how certain interventions (board orientations, mentoring programs, assignment to committees) influence organizational commitment or enhance individual governing capacity.

Finally, given that health, human service, and education organizations make up the largest share of the nonprofit sector, there are tens of thousands of real-world contexts in which to implement experiments, assessing program effectiveness through randomized controlled trials or natural experiments. While tools like MTurk and laboratory experiments offer options to recruit participants quickly, field experiments may be employed in partnership with many types of nonprofit service providers to assess the effects of various treatments or programs related to mental health, substance abuse, early childhood intervention, and workforce development, among others. While there are serious ethical considerations to be taken into account in designing control versus treatment groups in these settings, quite often there are ways to construct reasonable comparison groups within these contexts. While field experiments may be ideal for some of these applications of the behavioral approach, lab and survey experiments may be just as useful for answering some types of questions such as human resource inquiries related to motivations and attitudes of prospective employees and volunteers. In any case, nonprofit organizations can serve as real-world laboratories in which nonprofit scholars might design and carry out experiments to answer some of the sectors most salient questions. On the other side of this same coin, nonprofit practitioners should seek out university researchers to discuss their pressing questions and evaluation needs, and partner with researchers in the design of experiments that allow for evaluating the effectiveness of their efforts.

\section{References}

Bhati, A., \& Hansen, R. (2020). A literature review of experimental studies in fundraising. Journal of Behavioral Public Administration, 3(1).

Druckman, J. N. and C. D. Kam 2011. 'Students as experimental participants: A defense of the narrow data base', in Druckman, Green, Kuklinski, and Lupia (eds.), Cambridge Handbook of Experimental Political Science. Cambridge: Cambridge University Press. pp. 41-57.

James, O. Jilke, S. and Van Ryzin, G. 2017. "Introduction: Experiments in public management research," in O. James, S. Jilke, \& G. Van Ryzin (eds). Experiments in Public Management Research. Challenges and Contributions. Cambridge: Cambridge University Press. pp. 3-19

James, O. Jilke, S. and Van Ryzin, G. (2017). Experiments in public management research. Challenges and Contributions. Cambridge: Cambridge University Press.

Jurcevic, I., \& Fyall, R. (2019). Does a business-like approach to diversity in nonprofit organizations have a chilling effect on stakeholders? Journal of Behavioral
Public Administration, 3(1).

https://doi.org/10.30636/jbpa.31.100

Jilke \& Van Ryzin, 2017). "Survey experiments for public management research," in O. James, S. Jilke, \& G. Van Ryzin (eds). Experiments in Public Management Research. Challenges and Contributions. Cambridge: Cambridge University Press. pp. 117-138.

Tepe and Prokop (2017). "Laboratory experiments: Their potential for public management research," in O. James, S. Jilke, \& G. Van Ryzin (eds). Experiments in Public Management Research. Challenges and Contributions. Cambridge: Cambridge University Press. pp. 139164.

Tian, Y., Hung, C. and Frumkin, P. 2020. Breaking the nonprofit starvation cycle? An experimental test. Journal of Behavioral Public Administration. 3, 1 (Apr. 2020). DOI:https://doi.org/10.30636/jbpa.31.93.

Van Teunenbroek, Claire and René Bekkers. 2020. "Follow the crowd: Social information and crowdfunding donations in a large field experiment." Journal of Behavioral Public Administration 3(1):1-17. 